\title{
Analisis bauran komunikasi pemasaran di KSPPS Karisma Kantor Cabang Grabag dalam meningkatkan jumlah anggota
}

\author{
Vina Al Azizah, \& Andhatu Achsa* \\ Program Studi Manajemen, Fakultas Ekonomi, Universitas Tidar, Indonesia
}

\begin{abstract}
Abstrak Penelitian ini memiliki tujuan untuk mengetahui lebih dalam dan mendeskripsikan kondisi bauran komunikasi pemasaran yang diterapkan oleh KSPPS Karisma kantor cabang Grabag dalam menarik minat anggota sehingga jumlahnya meningkat. Kegagalan sebuah koperasi dalam memperoleh anggota salah satu faktornya adalah kurangnya media komunikasi pemasaran, sedangkan anggota adalah sumber keberlangsungan hidup bagi koperasi, maka dibutuhkan komunikasi pemasaran yang baik untuk menginformasikan adanya suatu produk sekaligus membujuk agar masyarakat melakukan pembelian. Metode deskriptif kualitatif menjadi metode yang digunakan dalam penelitian ini. Metode analisis data yang digunakan yaitu pengumpulan data, penyajian data yang ditemukan, dan kesimpulan. Data diperoleh dari observasi dan wawancara dengan purposive sampling sebagai teknik pengambilan sampelnya, dokumentasi, internet, dan studi kepustakaan yang dilaksanakan pada February 2020 sampai Mei 2020. Bauran komunikasi pemasaran yang digunakan oleh KSPPS Karisma cabang Grabag untuk meraih anggota adalah periklanan,penjualan personal, pemasaran dari mulut ke mulut, pemasaran langsung dan interaktif, dan hubungan masyarakat dan publisitas. Dalam penelitian ini, bauran komunikasi pemasaran yang digunakan oleh KSPPS Karisma cabang Grabag berpengaruh terhadap peningkatan jumlah anggota.
\end{abstract}

Kata kunci: KSPPS Karisma; bauran komunikasi pemasaran

\begin{abstract}
This study aims to know deeply and describe the conditions of marketing communication mix applied by KSPPS Karisma Grabag offices in attracting members' interest so that the numbers increase. The failure of a cooperative in getting members one of the factors is the lack of the marketing communication media, while members are source of survival for cooperatives, so good marketing communication is needed to inform the existence of a product and persuading the public to make a purchase. The qualitative descriptive method is used in this research. Data analysis methods used are data collection, presentation of data, and conclusions. Data obtained from observations and interviews with purposive sampling as a sampling technique, documentation, internet, and literatur study conducted on February to May 2020. The marketing communication mix used by KSPPS Karisma Grabag office to reach members is advertising, personal selling, word of mouth marketing, direct and interactive marketing, and public relations and publicity. In this study, the marketing communication mix used by KSPPS Karisma Grabag office affect on increasing number of members.
\end{abstract}

Keywords: KSPPS Karisma; marketing communication mix

JEL Classification: Do2; C44; Q12; D46; G31

* Penulis koresponden

E-mail: andhatuachsa@untidar.ac.id

(C) 2021 Azizah, \& Achsa. Artikel ini dimiliki oleh penulis yang dilisensikan dibawah Creative Commons Attribution 4.0 International License. Lisensi ini memungkinkan penggunaan, pendistribusian, dan pencetakan kembali tanpa batas pada media apa pun, asalkan penulis dan sumber sebenarnya disebutkan 


\section{PENDAHULUAN}

Sistem keuangan di Indonesia memiliki dua jenis yaitu perbankan yang merupakan perusahaan bidang keuangan yang aktivitasnya menghimpun dana melalui simpanan dari masyarakat dan melakukan penyaluran melalui kredit kepada masyarakat serta melayani jasa bank yang lain dan lembaga keuangan bukan bank yang jenisnya lebih beragam dan masing-masing jenisnya memiliki program kerja dan ciri khas sendiri (Muchtar, Rahmidani, \& Siwi, 2016). Kegiatan operasional bank diawasi oleh Bank Sentral (BI). Lembaga keuangan bukan bank kegiatannya diawasi oleh Departemen Keuangan yang dijalankan Bapepam LK. Berikut beberapa jenis lembaga keuangan non bank meliputi koperasi, pegadaian, perusahaan pembiayaan, pasar modal, perusahaan dana pensiun, perusahaan asuransi, dan perusahaan modal ventura (Soemitra, 2015). Pelaksanaan pembangunan nasional salah satunya dapat didorong dengan peran koperasi terhadap perekonomian (Mubarok, Jannah, \& Laksanawati, 2018). Koperasi memiliki beberapa jenis yaitu koperasi simpan pinjam, konsumsi, serba usaha, dan produksi (Kholid, Rahayu, \& Yaningwati, 2014).

Koperasi simpan pinjam (KSP) kegiatan usaha utamanya adalah menyimpan dan meminjamkan uang untuk memenuhi kebutuhan anggota (Kasmir, 2014). Berdasarkan jenis usaha, asas dan prinsipnya, koperasi dibedakan menjadi koperasi konvensional dan koperasi syariah (Safe'i, 2012). Peraturan Menteri KUKM menjelaskan pengertian bahwa KSPPS (Koperasi simpan, pinjam, dan pembiayaan syariah) merupakan koperasi di mana koperasi tersebut terbentuk dari Baitul Maal Wattamwil (BMT) yang memiliki kegiatan usaha seperti perbankan yaitu pembiayaan, simpanan, dan pinjaman yang dilakukan berdasarkan prinsip syariah termasuk juga di dalamnya mengelola wakaf, infaq, dan zakat (Perizinan Usaha Simpan Pinjam, 2018). KSPPS memiliki fungsi sebagai lembaga bisnis sekaligus fungsi sosial yang berupa menghimpun, mengelola, dan menyalurkan dana zakat, wakaf, dan infaq. KSPPS terdapat Dewan Pengawas Syariah yang bertanggung jawab mengawasi dan mengontrol agar kegiatan operasionalnya sesuai dengan prinsip syariah (Hidayat, 2016). Hal menonjol yang membedakan KSPPS dengan lembaga keuangan konvensional adalah terletak pada pembagian keuntungan antara anggota dengan pihak lembaga, di mana dalam KSPPS, nisbah bagi hasil telah disepakati kedua belah pihak (Buchori \& Prasetyo, 2014).

KSPPS ini didirikan dengan maksud memberikan dana kepada pedagang maupun usaha mikro dan memberikan fasilitas barupa pinjaman dana kepada masyarakat kalangan menengah ke bawah yang masih belum mendapatkan pelayanan dari lembaga bank lainnya (Wiliasih \& Shadrina, 2017). KSPPS diupayakan untuk pemberdayaan ekonomi anggota dan masyarakat pada umumnya melalui produk-produknya yang berupa mudharabah, murabahah, musyarakah, dan qard. KSPPS sebagai lembaga keuangan mikro berfungsi sebagai pihak penyalur dana kepada anggota yang memerlukan untuk kebutuhan pengembangan usaha melalui pemberian pembiayaan (Mujib, 2017). Sejauh ini KSPPS telah membantu ratusan ribu usaha mikro di seluruh Indonesia (Yusuf, 2016). Dana yang disalurkan kepada anggota yang membutuhkan merupakan dana yang berasal dari simpanan 
anggota lain. Selain pembiayaan, hadirnya KSPPS diharapkan bisa meningkatkan kesadaran masyarakat akan pentingnya mengatur dana untuk masa depan melalui simpanan atau menabung (Lisdawami \& Mawardi, 2017). Adanya kegiatan pembiayaan dan penyimpanan ini, membuat KSPPS berinisiatif membuat berbagai macam bentuk pembiayaan dan simpanan sesuai Syariah. Untuk mengenalkan produknya kepada masyarakat, maka usaha yang dilakukan oleh KSPPS adalah melalui komunikasi pemasaran yang tepat.

Salah satu KSPPS yang ada di Magelang adalah KSPPS Karisma yang memiliki cabang salah satunya di Kecamatan Grabag yang beralamat di Jl. Kyai Syiradj nomor 90 Kliwonan Grabag. KSPPS kantor cabang Grabag beroperasi sejak tahun 2008. KSPPS Karisma kantor cabang Grabag tetap eksis di tengah ketatnya persaingan di antara KSPPS atau BMT yang lain sesuai dengan pernyataan Kepala Sub Bagian Administrasi bahwa keanggotan KSPPS Karisma kantor cabang Grabag selalu mengalami kenaikan. Berikut adalah tabel yang menunjukkan kenaikan jumlah anggota.

Tabel 1. Jumlah Anggota di KSPPS Karisma kantor cabang Grabag periode Februari- Mei 2020

\begin{tabular}{lllll}
\hline Produk & Februari & Maret & April & Mei \\
\hline Pembiayaan & 1.914 & 2.103 & 2.229 & 2.310 \\
Simpanan & 32.037 & 32.260 & 32.306 & 32.320 \\
\hline
\end{tabular}

Data jumlah anggota di KSPPS Karisma kantor cabang Grabag menunjukkan bahwa keanggotaan KSPPS Karisma periode Februari hingga Mei 2020 mengalami kenaikan. Hal ini tentu tidak terlepas bagaimana KSPPS Karisma kantor cabang Grabag mengkomunikasikan produknya serta bagaimana bauran komunikasi pemasaran yang diterapkan.

Komunikasi merupakan proses pentransferan ide dari satu orang ke orang lain yang dimaksudkan untuk mengubah tingkah laku penerima (Triningtyas, 2016). Adanya komunikasi merupakan suatu proses untuk menciptakan kesamaan pemikiran antara sumber dengan penerima (Chrismardani, 2014). Adapun unsurunsur komunikasi ada 5 yaitu (Prasetya, 2018) antara lain (1) Sumber, adalah individu atau kelompok yang memiliki informasi atau gagasan untuk dibagikan; (2) pesan, adalah bentuk makna yang akan diberikan kepada penerima oleh sumber setelah mengalami proses decoding, (3) saluran merupakan media yang diaplikasikan untuk memindahkan pesan komunikasi dari sumber ke receiver; (4) penerima pesan yaitu individu atau lembaga yang dimaksudkan menjadi tujuan sumber; (5) respon, adalah reaksi penerima atas pesan yang didapatkan dari sumber.

Pemasaran adalah suatu kegiatan pertukaran yang dilakukan oleh perusahaan ataupun organisasi kepada pelanggannya yang menguntungkan (Firmansyah, 2019). Melalui pemasaran, masyarakat dapat mengetahui informasi terkait barang dan jasa untuk memenuhi kebutuhan dan keinginannya (Rachmawati, Teknologi, \& Semarang, 2017). Komunikasi pemasaran baik secara langsung maupun tidak 
langsung untuk membujuk dan meyakinkan konsumen agar membeli produk yang ditawarkan (Fitriah, 2018). Komunikasi berperan penting untuk perusahaan karena tanpa komunikasi, perusahaan tidak bisa memberitahukan keberadaan produknya kepada konsumen atau masyarakat. Komunikasi pemasaran menjadi sebuah kebutuhan bagi perusahaan karena berperan sebagai interaksi antara produsen dengan konsumen untuk menginformasikan produk yang akan dijual dan mempengaruhi atau membujuk konsumen agar membeli produk yang ditawarkan (Srisusilawati, 2017). Komunikasi pemasaran perlu dipahami secara mendalam oleh pemasar agar menghasilkan komunikasi pemasaran yang efektif sebagai kunci keberhasilan perusahaan dalam menjual produknya (Supit, 2016). Komunikasi pemasaran diharapkan konsumen mengalami 3 tahap perubahan yaitu pertama, perubahan pengetahuan dengan mengharapkan konsumen atau masyarakat mengetahui adanya suatu produk barang atau jasa; kedua, perubahan sikap yaitu konsumen diharapkan memiliki rasa baik rasa suka, tidak suka, maupun rasa ingin membeli terhadap suatu produk karena telah mengetahui keberadaannya; ketiga, perubahan perilaku yaitu konsumen diharapkan akan melakukan suatu tindakan yang diakibatkan oleh pengetahuan dan sikap konsumen, apakah produk yang ditawarkan akan dibeli atau tidak (Syarif, 2019).

Bauran komunikasi pemasaran terdiri atas gabungan antara penjualan personal, iklan, humas dan publisitas, promosi penjualan, serta acara dan pengalaman di mana perusahaan menggunakannya untuk mengkomunikasikan produk yang bersifat persuasif dan membangun hubungan dengan pelanggan atau masyarakat (Saleh \& Said, 2019). Kotler dan Keller (2016) dalam bukunya menjelaskan bahwa bentuk bauran komunikasi pemasaran terdiri atas beberapa bentuk yaitu (1) periklanan adalah komunikasi non pribadi yang berbayar berupa penyajian pesan atau ide tentang suatu produk yang bersifat membujuk dan menggiring masyarakat agar tertarik pada produk tersebut biasanya berupa televisi, radio, surat kabar, majalah,maupun brosur; (2) promosi penjualan yaitu beragam insentif, potongan, atau pemberian jangka pendek sebagai alat menarik respon pembeli secara lebih cepat biasanya berupa diskon, barang gratis, souvenir, dan hadiah; (3) acara dan pengalaman merupakan kegiatan yang diselenggarakan oleh suatu badan atau organisasi di mana kegiatan tersebut didukung dan didanai oleh perusahaan; (4) hubungan masyarakat dan publisitas yaitu berbagai macam kegiatan yang dikelola untuk membangun dan melindungi citra serta mempromosikan perusahaan dengan membina hubungan dengan pelanggan atau masyarakat; (5) pemasaran langsung, yaitu penggunaan media untuk memberi informasi produk kepada konsumen secara langsung dan mengharap respon dan dialog dari konsumen; (6) pemasaran interaktif yaitu pengunaan media online untuk menyampaiakan informasi mengenai produk kepada konsumen yang menyediakan tempat bagi konsumen agar bisa terlibat di dalamnya. Dengan pemasaran interaktif, pesan dapat diubah tergantung dari respon seseorang. Tahun ke tahun penggunaan internet di Indonesia mengalami peningkatan (Kurnianti, 2017). Hal ini sangat bisa dimanfaatkan siapapun untuk mempromosikan suatu produk kepada masyarakat. Peningkatan jumlah anggota, menurut peneliti tidak lepas dari bagaimana KSPPS Karisma kantor cabang Grabag mengkomunikasikan produk 
yang ditawarkan serta bagaimana bauran komunikasi pemasaran yang diterapkan. Penelitian ini memiliki tujuan untuk mengetahui secara rinci dan mendalam serta mendiskripsikan kondisi bauran komunikasi pemasaran yang diterapkan oleh KSPPS Karisma kantor cabang Grabag sehingga berhasil meningkatkan jumlah anggota.

\section{METODE PENELITIAN}

1. Jenis penelitian dan data yang diperlukan

Jenis penelitian dalam penelitian ini adalah kualitatif deskriptif. Jenis kualitatif deskriptif dipilih untuk menggambarkan kegiatan dan kondisi bauran komunikasi pemasaran yang diterapkan di KSPPS Karisma kantor cabang Grabag.

Data primer diperlukan dalam penelitian ini dan diperoleh melalui observasi dan wawancara pihak KSPPS Karisma kantor cabang Grabag dengan periode waktu pada Februari sampai dengan Mei 2020 dan data sekunder yang didapat dari internet, jurnal, dan buku yang sesuai dengan masalah dalam penelitian ini.

\section{Metode pengumpulan data}

Dalam mengumpulkan data, peneliti menggunakan metode observasi yaitu pengamatan secara langsung, metode wawancara. Wawancara dilakukan pada 2 responden dari 12 jumlah seluruh populasi yang merupakan karyawan dengan rincian sebagai berikut, 1 manajer, 1 bagian administrasi, 1 pihak funding, $3 \mathrm{AO}$, dan 6 kolektor. Dalam menentukan sampel, peneliti menggunakan teknik purposive sampling. Teknik purposive sampling dilakukan dengan cara menentukan sample berdasarkan pada pertimbangan kriteria tertentu guna memperoleh data sesuai dengan yang dibutuhkan (Sugiyono, 2012). Wawancara dilakukan pada Manajer KSPPS Karisma kantor Cabang Grabag dan Kepala sub bagian administrasi KSPPS Karisma kantor Cabang Grabag. Manajer dan kepala sub bagian administrasi dipilih sebagai responden karena dianggap menguasai kegiatan yang sesuai dengan tujuan penelitian, serta dokumentasi yang diperoleh melalui artikel, penelitian terdahulu, buku dan internet.

\section{Metode analisis data}

Untuk menganalisis data yang telah diperoleh, peneliti menggunakan metode analisis data yang berupa pengumpulan data yang diperlukan, penyajian data yang disertai analisis mengenai gambaran objek penelitian, dan verifikasi data atau kesimpulan.

\section{HASIL DAN PEMBAHASAN}

Untuk mengenalkan produknya, KSPPS Karisma kantor cabang Grabag harus mengkomunikasikan produknya kepada masyarakat agar keberdaan produk tersebut diketahui secara lengkap oleh masyarakat. Melalui komunikasi pemasaran, KSPPS Karisma kantor cabang Magelang dapat menggunakan bauran komunikasi pemasaran sebagai sarana dalam upaya meningkatkan jumlah anggota. 
Berdasarkan hasil wawancara dan observasi yang diperoleh, berikut adalah bauran komunikasi pemasaran yang diterapkan oleh KSPPS Karisma kantor cabang Grabag sebagai berikut.

\section{Periklanan}

Kegiatan periklanan yang dilakukan KSPPS Karisma kantor cabang Grabag meliputi:

a. Video mengenai produk dan simulasi pengajuan yang ditayangkan setiap hari di ruang tunggu sehingga mau tidak mau, anggota yang berkunjung akan mendengarkan dan melihat tayangan tersebut. Video ini ditayangkan di TV yang dipasang di ruang tunggu bertujuan untuk mengenalkan produk dan mencontohkan bagaimana proses pengajuan untuk menggunakan produkproduk KSPPS Karisma.

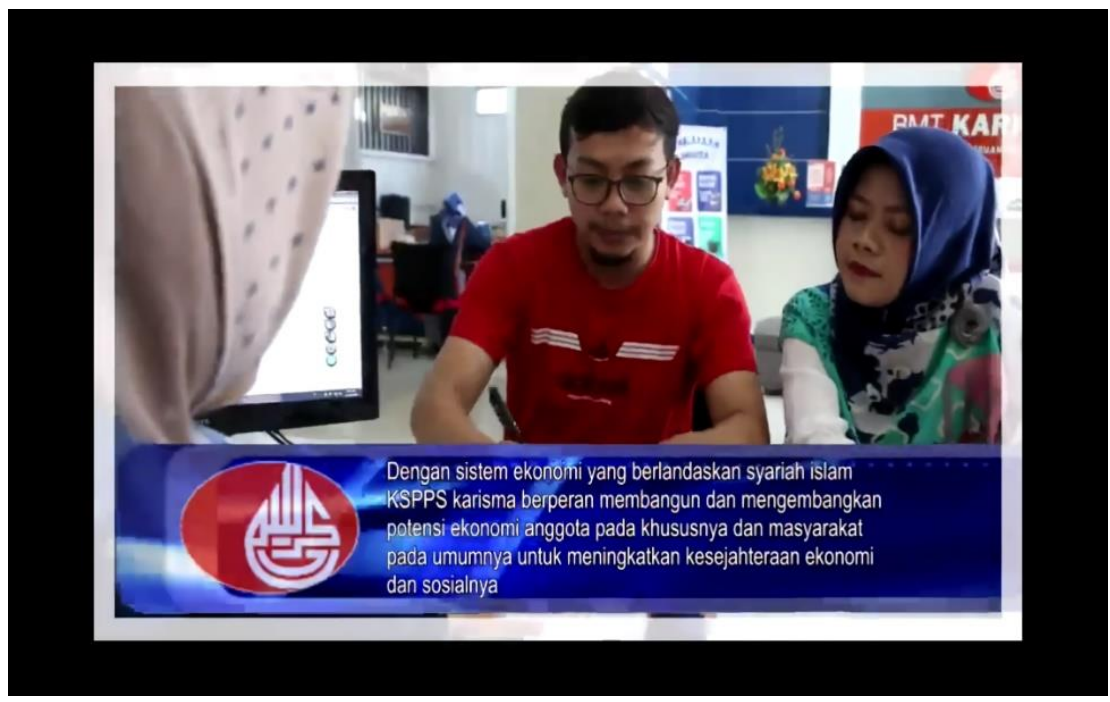

Gambar 1. Salah satu video tentang KSPPS Karisma kantor cabang Grabag yang ditampilkan di ruang tunggu

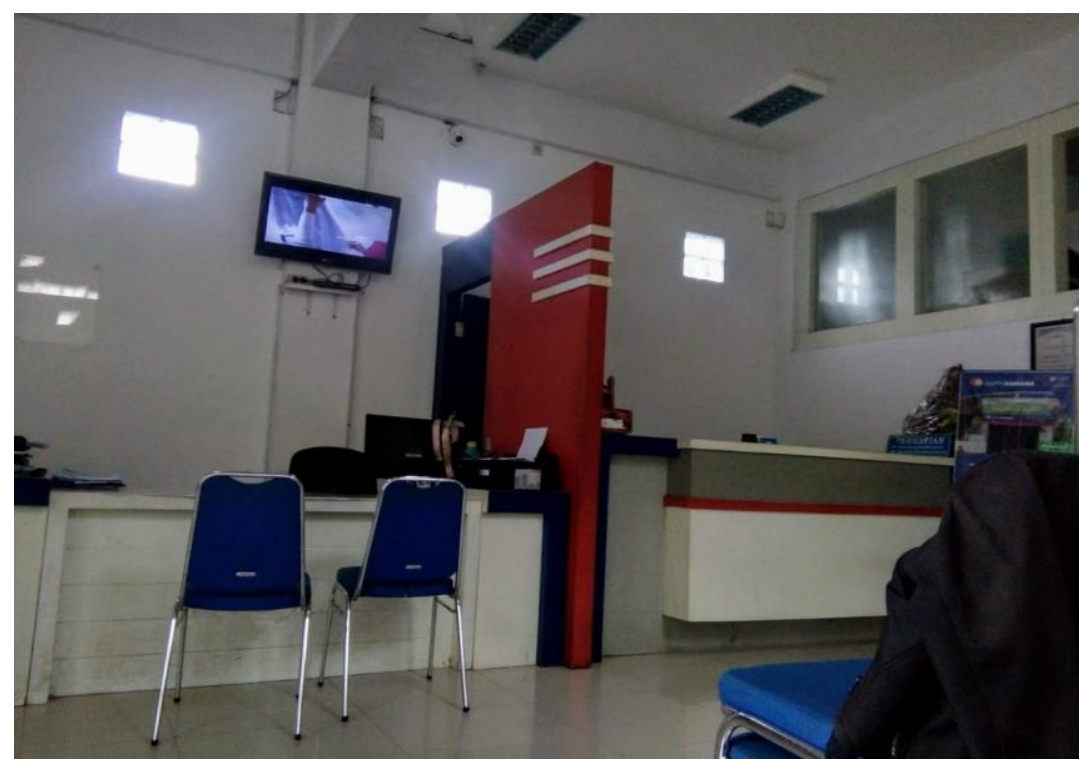

Gambar 2. Ruang tunggu di KSPPS Karisma kantor cabang Grabag 
b. Selebaran atau brosur berupa selebaran yang berisi satu produk simpanan KSPPS Karisma yang di dalamnya berisi pengertian, syarat, dan nisbah bagi hasil masing-masing produk serta brosur yang berisi informasi, syarat, dan ketentuan pembiayaan.

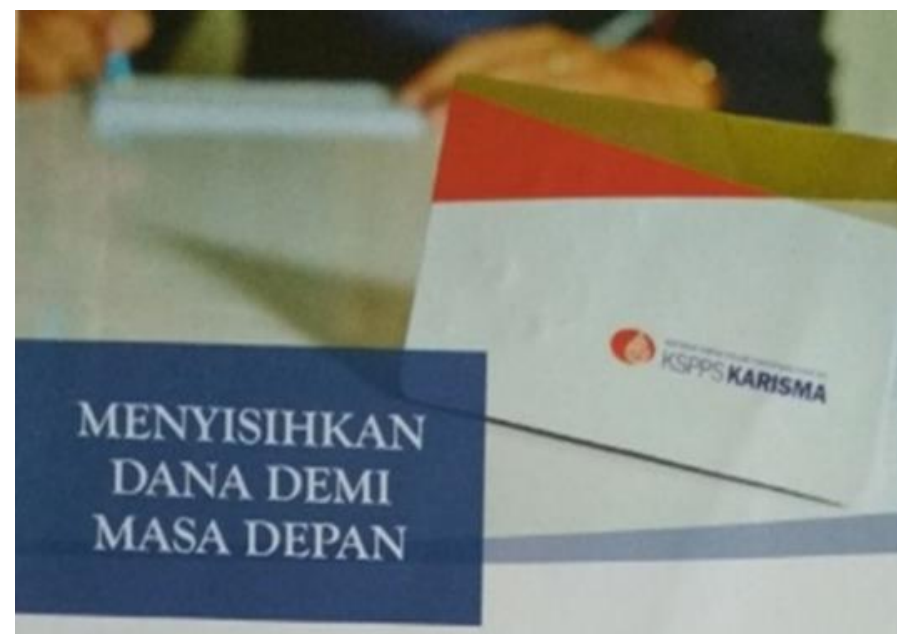

Siaga Karisma adalah layanan Simpanan Anggota di KSPPS Karisma, dimana dana dari Anggota dikelola oleh KSPPS Karisma dan Anggota mendapatkan bag hasil.

- Setoran dan penarikan Siaga Karisma dapat dilakukan sewaktu-waktu (selama kas buka).

- Setoran awal Rp25.000,00

- Pemeliharaan saldo minimal Rp $15.000,00$

- Simpanan diatas Rp50.000,00 bisa diambil oleh petugas KSPPS Karisma.

- Nisbah bagi hasil (Anggota : KSPPS Karisma) $=9: 91$

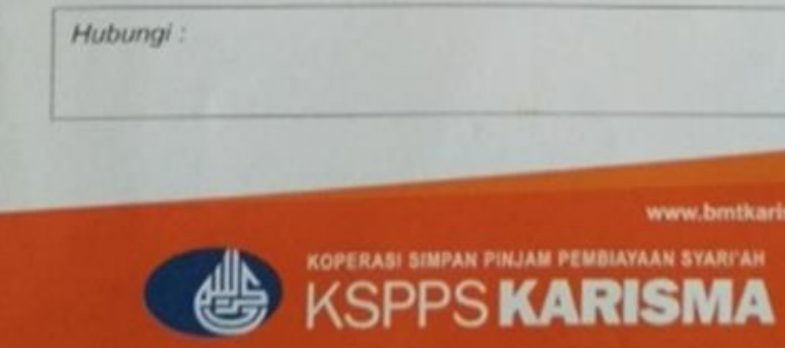

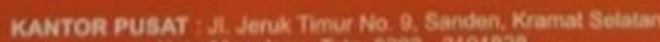
Kota Magolang Tolp 0203 - 3101028

Gambar 3. Brosur KSPPS Karisma Magelang

c. Memasang banner di tempat strategis di area kantor seperti di teras kantor dan di dekat customer service.

d. Menyediakan majalah Karisma di ruang tunggu agar anggota yang berkunjung membacanya sehingga mengetahui bagaimana sejarah, kegiatan, dan produk-produk yang ditawarkan oleh KSPPS Karisma. 


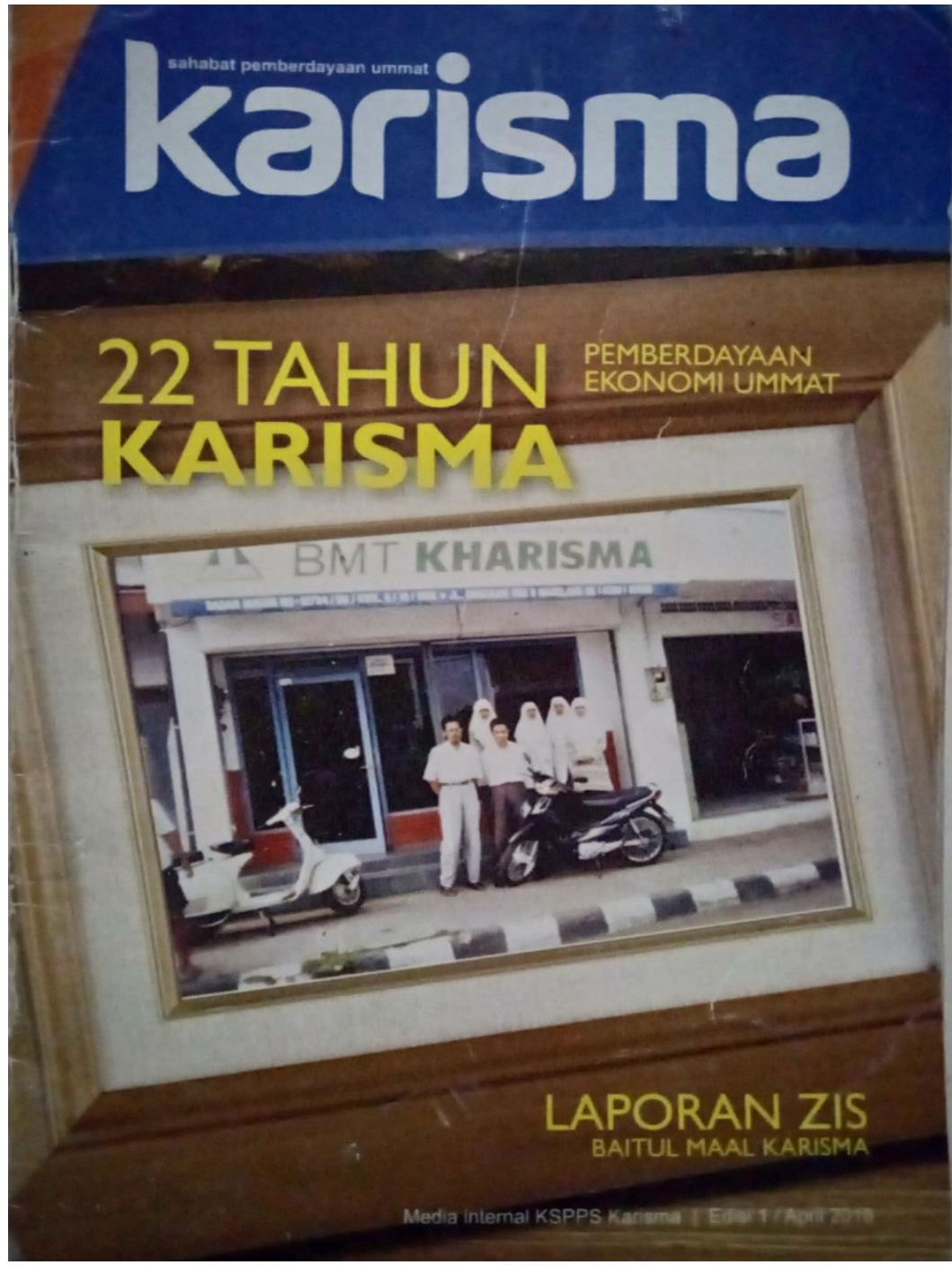

Gambar 4. Majalah KSPPS Karisma Magelang

e. Periklanan melalui radio. Periklanan melalui radio dinilai mampu menjangkau masyarakat lebih luas yang tidak bisa menemukan periklanan seperti brosur, banner, majalah, dan video.

\section{Promosi Penjualan}

Berikut adalah beberapa jenis promosi penjualan yang dilakukan oleh KSPPS Karisma kantor cabang Grabag :

a. Menawarkan nisbah bagi hasil yang sama-sama menguntungkan bagi anggota maupun pihak KSPPS Karisma.

b. Memberikan THR kepada anggota terpilih pada hari lebaran dan memberikan bantuan bagi anggota yang mengalami kesuliatan

3. Hubungan Masyarakat (Humas) dan Publisitas

Hubungan masyarakat dan publisitas berkaitan dengan citra KSPPS Karisma di mata anggota dan masyarakat sekitar serta menjaga tingkat kepercayaan anggota. 
a. Rapat Anggota Tahunan, RAT dilaksanakan dengan mengundang beberapa anggota sebagai perwakilan yang digilir setiap tahunnya. Dalam RAT juga dibahas mengenai kesepakatan bagi hasil.

b. Donasi Amal, KSPPS Karisma memiliki berbagai macam kegiatan amal seperti pemberian santunan kepada anak yatim, memberikan bantuan kepada orang sakit, memberi sumbangan pada daerah terdampak bencana, dan menyediakan ambulans gratis. Setiap kantor cabang diperbolehkan menambah kegiatan amal atau kegiatan sosial lainnya berdasarkan persetujuan divisi maal.

c. Menjadi sponsor dalam kegiatan seminar

d. Mengadakan kegiatan donor darah di mana kegiatan tersebut diselenggarakan di kantor pusat dan diikuti oleh semua kantor cabang. Kegiatan donor darah tersebut dilaksanakan dalam jangka waktu 3 bulan.

e. Pemberian beasiswa untuk pendidikan jenjang SMA dan perguruan tinggi

f. Pentasyarufan hewan kurban ke desa tertinggal

g. Pengajian yang dilakasanakan pada hari Jumat setiap bulannya. Pengajian dilaksanakan di masjid terdekat yang diikuti oleh seluruh karyawan dan masyarakat sekitar kantor KSPPS Karisma Grabag dan diisi oleh tokoh agama di daerah setempat.

\section{Pemasaran Interaktif dan Pemasaran Langsung}

Sebagai upaya agar dapat berkomunikasi secara langsung atau meminta respon kepada masyarakat, maka KSPPS Karisma kantor cabang Grabag menerapkan pemasaran interaktif dan pemasaran langsung. Pemasaran langsung dan pemasaran interaktif yang dilakukan oleh KSPPS Karisma kantor cabang Grabag yaitu pemanfaatan internet melalui website, youtube, dan sosial media. Namun penggunaan media sosial yang dipilih belum dimanfaatkan secara optimal. KSPPS Karisma kurang aktif dalam memperbarui postingan. Follower akun sosial media dari KSPPS Karisma pun masih kurang.

\section{Pemasaran dari mulut ke mulut}

Kepala KSPPS Karisma kantor cabang Grabag, Dedy Setiawan, S.E., mengatakan bahwa banyak anggota yang mendapat informasi melalui pengalaman tetangga yang menjadi anggota KSPPS Karisma dan dealer atau Lembagalembaga lain yang bekerjasama dengan KSPPS Karisma kantor cabang Grabag.

\section{Penjualan Personal.}

Penjualan personal biasanya dilakukan oleh Account Officer, Collector, dan petugas Funding. AO bertugas memperluas pasar dan mencari anggota baru dengan strategi jemput bola yaitu mendatangi calon anggota hingga tahap pengajuan. Setelah pengajuan diterima kemudian akan ditindaklanjuti oleh kolektor. Kusniadji (2017) menjelaskan bahwa penjualan personal memiliki komunikasi dua arah yang dapat menciptakan dialog antara penjual dan calon pembeli. Adanya komunikasi tersebut, pihak KSPPS Karisma kantor cabang Grabag dapat memberikan pemahaman lebih rinci mengenai produk yang ditawarkan dan mendapat reaksi langsung dari calon anggota. 
Untuk produk simpanan, petugas funding akan mendatangi sekolah-sekolah, perkantoran atau lembaga tertentu untuk menawarkan dan mempresentasikan berbagai produk simpanan yang disediakan. Penjualan personal dinilai paling efektif untuk meyakinkan calon anggota.

\section{KESIMPULAN}

Bauran komunikasi pemasaran yang diterapkan di KSPPS Karisma kantor cabang Grabag dapat menarik minat masyarakat menjadi anggota sehingga jumlah anggota dalam setiap bulan selalu mengalami kenaikan. Bauran komunikasi pemasaran yang digunakan oleh KSPPS Karisma kantor cabang Grabag di antaranya adalah periklanan, promosi penjualan, humas dan publisitas, pemasaran interaktif dan pemasaran langsung, pemasaran dari mulut ke mulut serta penjualan personal. Humas dan publisitas menjadi alat komunikasi pemasaran dengan program sosial yang paling beragam. Sedangkan penjualan personal dengan strategi jemput bolanya dinilai paling efektif dalam membujuk calon anggota. Masing-masing bauran komunikasi pemasaran yang digunakan memiliki kekurangan dan kelebihan sehingga pihak KSPPS Karisma kantor cabang Grabag perlu terus melakukan perbaikan dan pembaharuan program.

Diharapkan bagi penelitian selanjutnya agar mengembangkan dan melakukan wawancara lebih mendalam dan responden yang lebih banyak dari pihak KSPPS Karisma cabang Grabag yang dapat memberikan informasi terkait penelitian agar mendapat hasil yang lebih baik.

\section{UCAPAN TERIMAKASIH}

Penulis mengucapkan terimakasih kepada seluruh pihak Program Studi Manajemen Fakultas Ekonomi Universitas Tidar yang telah membimbing dan memberi masukan untuk perbaikan artikel ini dan pihak KSPPS Karisma kantor cabang Grabag atas kesedian sebagai lokasi penelitian.

\section{DAFTAR PUSTAKA}

(1) Buchori, I., \& Prasetyo, A. (2013). Pengaruh Tingkat Pembiayaan Mudharabah Terhadap Tingkat Rasio Profitabilitas Pada Koperasi Jasa Keuangan Syariah (KJKS) Manfaat Surabaya. EL-Qist, 04(01), 706-734. http://elqist.uinsby.ac.id/index.php/elqist/article/view/9

(2) Chrismardani, Y. (2014). Komunikasi Pemasaran Terpadu: Implementasi Untuk UMKM. Jurnal NeO-Bis, 8(2), 176-189. https://journal.trunojoyo.ac.id/neobis/article/view/472

(3) Firmansyah, A. (2019). Pemasaran : Dasar dan Konsep. Pasuruan: Penerbit Qiara Media.

(4) Fitriah, M. (2018). Komunikasi Pemasaran Melalui Desain Visual. Yogyakarta: Deepublish. 
(5) Hidayat, F. (2016). Sistem Pengawasan Pada Koperasi Simpan Pinjam dan Pembiayaan Pyariah (KSPPS) Dalam Mewujudkan Syariah Compliance. Mahkamah, 2(1), 383-407. https://journal.iaimnumetrolampung.ac.id/index.php/jm/article/view/47

(6) Kasmir. (2014). Bank dan Lembaga Keuangan Lainnya. Jakarta: Raja Grafindo Persada.

(7) Kholid, I., Rahayu, S. M., \& Yaningwati, F. (2014). Penilaian Kesehatan Koperasi Simpan Pinjam Berdasarkan Peraturan Menteri Koperasi Dan Usaha Kecil Dan Menengah Republik Indonesia Nomor 14/PER/M.KUKM/XII/2009 (Studi pada Koperasi SImpan Pinjam Adi Wiyata Mandiri Kab. Blitar). Jurnal Administrasi Bisnis (JAB), 15(2), 1-6.

http://administrasibisnis.studentjournal.ub.ac.id/index.php/jab/article/view/664

(8) Kotler, P., \& Keller, K. (2016). Manajemen Pemasaran (12th ed.). Jakarta: Indeks.

(9) Kurnianti, A. W. (2017). Komunikasi Pemasaran Transportasi Online NGuberJEK. Jurnal Komunikasi Dan Kajian Media, 1(1), 69-85. https://jurnal.untidar.ac.id/index.php/komunikasi/article/view/392

(10) Kusniadji, S. (2017). Kontribusi Penggunaan Personal Selling Dalam Kegiatan Komunikasi Pemasaran Pada Era Pemasaran Masa Kini. Jurnal Komunikasi, 9(2), 176-183. http://dx.doi.org/10.24912/jk.v9i2.1078

(11) Lisdawami, I. M., \& Mawardi, I. (2017). Pengembangan Produk Funding KSPPS BMT Amanah Ummah Jawa Timur. Jurnal Ekonomi Syariah Teori Dan Terapan, 4(11), 889-901. http://dx.doi.org/10.20473/vol4iss201711pp889-901

(12) Mubarok, N., Jannah, S. A., \& Laksanawati, S. (2018). Analisis Identifikasi Masalah Utama Koperasi Di Kabupaten Banyuasin Dalam Mewujudkan Kesejahteraan Anggota. I-Economic, 4(2), 194-213. https://doi.org/10.19109/ieconomics.v4i2.3039

(13) Muchtar, B., Rahmidani, R., \& Siwi, M. K. (2016). Bank dan Lembaga Keuangan Lain. Jakarta: Kencana.

(14) Mujib, A. (2017). Dewan Pengawas Syariah (DPS) pada Lembaga Keuangan Mikro Syariah di Wilayah Jawa Tengah. Az Zarqa', 9(125-145). http://ejournal.uinsuka.ac.id/syariah/azzarqa/article/view/1433

(15) Prasetya, B. (2018). Komunikasi Pemasaran Terpadu (Pendekatan Tradisional Hingga Era Media Baru). Malang: UB Press.

(16) Rachmawati, R., Teknologi, J., \& Semarang, U. N. (2017). Peranan Bauran Pemasaran (Marketing Mix) terhadap Peningkatan Penjualan (Sebuah Kajian terhadap Bisnis Restoran). Jurnal Kompetensi Teknik, 2(2), 143-150.

(17) RI, M. K. dan U. K. M. Perizinan Usaha Simpan Pinjam. (2018).

(18) Safe'i, A. (2012). Koperasi Syariah: Tinjauan Terhadap Kedudukan dan Peranannya dalam Pemberdayaan Ekonomi Kerakyatan. Media Syariah, 14(1), 39-64. https://jurnal.ar-raniry.ac.id/index.php/medsyar/article/view/1718

(19) Saleh, M., \& Said, M. (2019). Konsep dan Strategi Pemasaran. Makassar: Sah Media

(20) Soemitra, A. (2015). Bank dan Lembaga Keuangan Syariah. Jakarta: Prenademedia Group.

(21) Srisusilawati, P. (2017). Kajian Komunikasi Pemasaran Terpadu Dalam Mendorong Keputusan Pembelian Jasa Perbankan. Amwaluna: Jurnal Ekonomi Dan Keuangan Syariah, 1(1), 1-18. https://doi.org/10.29313/amwaluna.v1i1.1993

(22) Sugiyono. (2012). Metode Penelitian Bisnis. Bandung: Alfabeta.

(23) Supit, E. O. J. (2016). Kajian Strategi Komunikasi Pemasaran Rumah Panggung Di Woloan. E-Journal "Acta Diurna," V(5).

https://ejournal.unsrat.ac.id/index.php/actadiurnakomunikasi/article/view/13539 
(24) Syarif, N. (2019). Komunikasi Kontemporer : Bisnis Islam di Era Digital. Yogyakarta: Deepublish.

(25) Triningtyas, D. (2016). Komunikasi Antar Pribadi. Magetan: AE Media Grafika.

(26) Wiliasih, R., \& Shadrina, F. (2017). Faktor Dominan Yang Memengaruhi Keputusan Nasabah Untuk Menabung Di Bank Syariah, BPRS, Dan KSPPS (Islamic Cooperatives). Jurnal Nisbah, 3(2), 442-461. https://doi.org/10.30997/jn.v3i2.911

(27) Yusuf, B. (2016). Analisis Tingkat Kesehatan Koperasi Syariah. Esensi: Jurnal Bisnis Dan Manajemen, 6(1), 101-112. https://doi.org/10.15408/ess.v6i1.3124 